\title{
Aortoiliac Arteriovenous Fistulae Simulating Deep Vein Thrombosis
}

\author{
Germán J Chaud*, Filippa A Pablo, Wainscheinker Ezequiel, Parisi Andrés, Guillermo Paladini and Alejandro \\ M Martínez Colombres
}

Department of Cardiovascular Surgery at Hospital Privado Universitario de Córdoba, Argentina

Submission: March 05, 2018; Published: April 20, 2018

*Corresponding author: Chaud Germán J, Department of Cardiovascular Surgery at Hospital Privado Universitario de Córdoba, Córdoba, Naciones Unidas 346, Argentina, Tel: 5403514 688236; Email: germanchaud@gmail.com

\section{Abstract}

Incidence of aorto-caval fistulae is quite low, ranging from 0.22 to $6.04 \%$ of all abdominal aortic aneurysm. One of the rare forms of abdominal aortic aneurysm rupture is rupture into great abdominal veins, such as the inferior vein cava (IVC) or the iliac veins. The typical clinical presentation includes abdominal pain, a pulsatile abdominal mass, an abdominal bruit and acute dyspnea. Morbidity and mortality will be affected by the acute presentation, preoperative recognition of the fistula, the extent of cardiac failure, coronary disease and other risk factors of atherosclerosis. Correct operative management includes expeditious control of the bleeding, greater care to avoid embolization through the fistula, use of blood salvage, and only selective caval interruption.

\section{Introduction}

Arteriovenous fistula (AVF) of the infrarenal aorta is a wellknown clinical entity. Incidence of aorto-caval fistulae is quite low, ranging from 0.22 to $6.04 \%$ of all abdominal aortic aneurysm (A.A.A). Aorto-caval fistula was first described by Syme in 1831, and the first successful repair of spontaneous ACF was performed by DeBakey et al. in 1954 et al and then by Cooley et al. in 1955 [1].

One of the rare forms of abdominal aortic aneurysm rupture is rupture into great abdominal veins, such as the inferior vein cava (IVC) or the iliac veins of left renal vein, with the formation of direct or indirect aorto-caval fistula (ACF). Rupture of an aortoiliac aneurysm into the inferior vena cava or iliac vein carries a better prognosis than retroperitoneal, intraperitoneal, or enteric rupture. The most common cause of communication between the abdominal aorta (or iliac arteries) and adjacent venous system, is aneurysm erosion. The majority of aneurysms are atherosclerotic in origin, other causes are syphilitic or mycotic aneurysms, aneurysmal lesion seen in Marfan's syndrome, EhlersDanlos syndrome, or Takayasu's arteritis. There are rare reports describing neoplasm, causing an aorto-caval fistula as well as ACF due to penetrating injuries or blunt trauma $[2,3]$.

The typical clinical presentation includes abdominal pain, a pulsatile abdominal mass, an abdominal bruit and acute dyspnea. The operative mortality rate of AVF repairs ranges from 16\%$66 \%$. The ideal approach to control bleeding would be to snare the proximal IVC and the distal portion of the AVF.
The control of the venous bleeding from fistula is challenging Manual compression distally and proximally to the fistula is a useful manoeuvre. The transfemoral insertion of an occlusive balloon catheter is another way to stop the venous bleeding. If a surgeon cannot control bleeding originate from fistula, it may be necessary to ligate the vena cava inferior. The aortic aneurysm repair is done once the fistula has been closed however, this can be difficult given the adhesions between the arteries and the vein [2]. We presented a single case of aorto iliac fistulae presented as inferior limb thrombosis.

\section{Case Report}

A 73-year-old male patient consulted for dyspnea and edema in the left lower limb of several days of evolution. As background, it referred, severe COPD, 2 episodes of ischemic stroke several years before which left no sequelae of importance and high digestive hemorrhage which led to peritonitis that became laparotomy and perforated peptic ulcer raffia 10 years before. On emergency room the patient was stable hemodynamically with a tendency to tachypnea. The physical examination called attention to the presence of abdominal thrill at the infraumbilical level. Given these findings, it was decided to perform a thoracoabdominal multislice computed tomography which reported interstitial pulmonary edema without findings compatible with TEPA, Aneurysm of the abdominal aorta of $50 \mathrm{~mm}$ anteroposterior diameter complicated with a fistula to the left primitive iliac vein (Figure 1 \& 2). We also performed a venous doppler of lower 
limbs which reported a left femoral vein with slow venous return without elements suggestive of thrombosis. Due to pulmonary compromise, emergency surgery was decided after a careful dissection and iliac vein control with continuous prolene suture in Aorto-Bifemoral bypass with bifurcated 16 x 8mm Dacron prosthesis was performed. The patient had a good clinical course and was discharged 15 days after the procedure due to pulmonary complications.

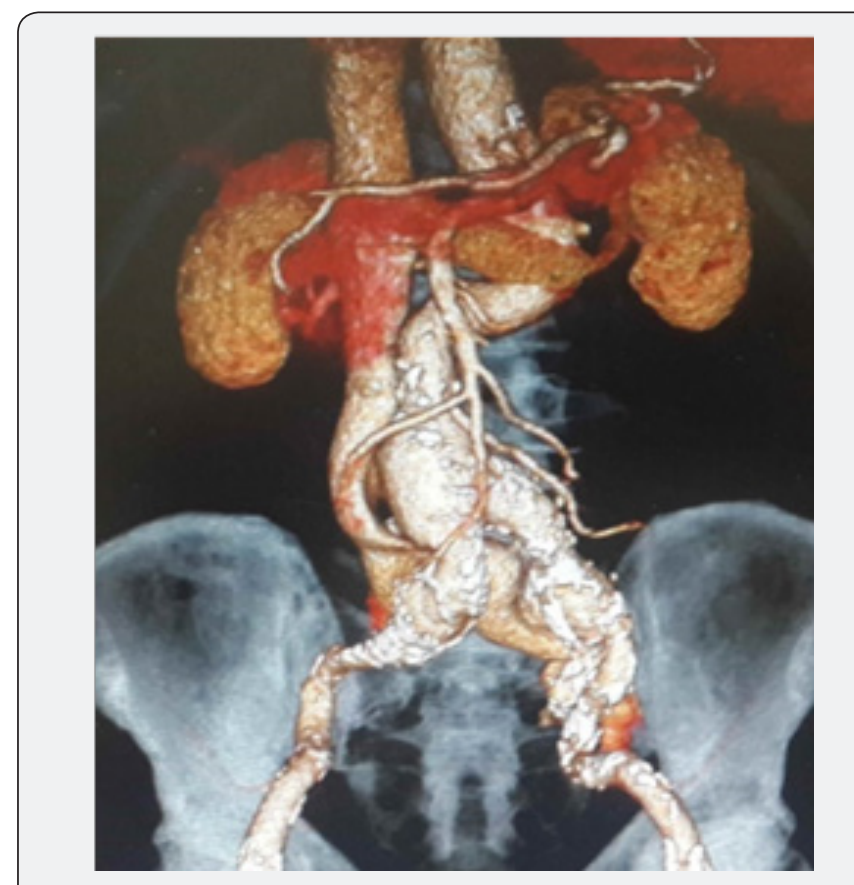

Figure 1: 3D multislice computed tomography reconstruction where lliaca aorto fistulae is identified.

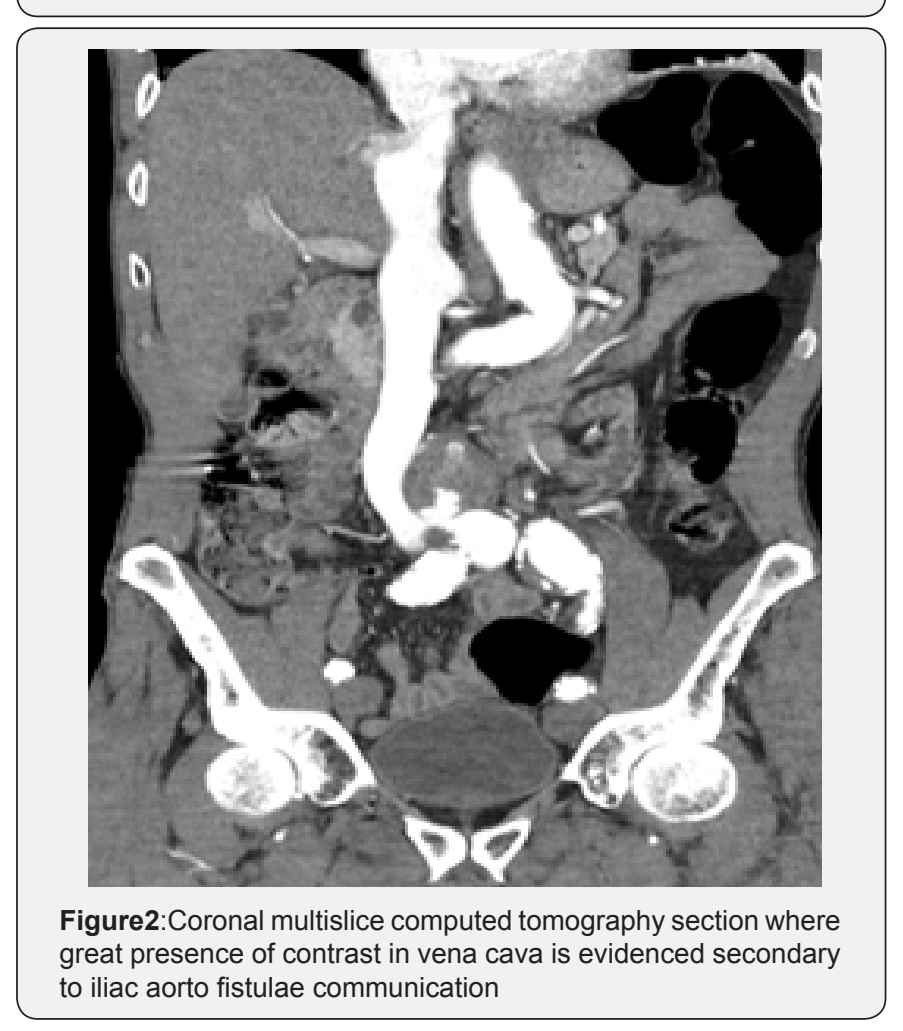

\section{Discussion}

Recently a few cases reports shown better results in the treatment of AVF and specially arterial lesions as a complication of lumbar-disc surgery with stents graft. However, endovascular repair for ACF has its complications such persistent communication between the aneurysm sac and the inferior vena cava can theoretically, lead to a high-flow type II endoleak. Aortocaval fistulas developing after endovascular repair of abdominal aortic aneurysm have also been described [4]. Even inconclusive and expensive we do not unable to perform endovascular procedures for aortic emergencies due to insufficient funding and lack of readily available endograft.

Morbidity and mortality will be affected by the acute presentation, preoperative recognition of the fistula, the extent of cardiac failure, coronary disease and other risk factors of atherosclerosis [5]. Our case even unique had success due to a rapid diagnosis and correct control of iliac vein. We had the problem of reintervention but we could control the fistulae and the aneurysm correctly.

\section{Conclusion}

Careful physical examination and increased awareness improve chances of preoperative diagnosis. In patients with acute presentation, expeditious surgical treatment is mandatory. Correct operative management includes expeditious control of the bleeding, greater care to avoid embolization through the fistula, use of blood salvage, and only selective caval interruption. Unfortunately, because of poor economic conditions in developing countries we have not use endograft in this cases but we must discussed in future if it's possible and when to use it.

\section{Ethical Responsibilities}

a) Protection of people and animals: The authors state that no human or animal experiments have been performed for this research.

b) Confidentiality of the data: The authors state that they have followed the protocols of their work center on the publication of patient data.

c) Right to privacy and informed consent: The authors state that no patient data appears in this article.

\section{References}

1. Davidovic L, Dragas M, Cvetkovic S, Kostic D, Cinara I, et al. (2011) Twenty years of experience in the treatment of spontaneous aortovenous fistulas in a developing country. World J Surg 35(8): 18291834.

2. Cinara IS, Davidovic LB, Kostic DM, Cvetkovic SD, Jakovljevic NS, et al. (2005) Aorto-caval fistulas: A review of eighteen years experience. Acta Chir Belg 105(6): 616-620.

3. Davis PM, Gloviczki P, Cherry KJ, Toomey BJ, Stanson AW, et al. (1998) Aorto-caval and ilio-iliac arteriovenous fistulae. Am J Surg 176(2): 115-118.

4. Canaud L, Hireche K, Joyeux F, D’Annoville T, Berthet JP, et al. (2011) 
Endovascular repair of aorto-iliac artery injuries after lumbar-spine surgery. Eur J Vasc Endovasc Surg 42(2): 167-171.

5. Kondo N, Takahashi K, Takeuchi S, Ito K (2011) Surgical Repair of Arteriovenous Fistula Associated with Iinfrarenal Aorto-iliac Aneurysm: Report of Two Contrasting Cases. Ann Vasc Dis 4(2): 150153.

\section{Your next submission with Juniper Publishers} will reach you the below assets

- Quality Editorial service

- Swift Peer Review

- Reprints availability

- E-prints Service

- Manuscript Podcast for convenient understanding

- Global attainment for your research

- Manuscript accessibility in different formats

(Pdf, E-pub, Full Text, Audio)

- Unceasing customer service

Track the below URL for one-step submission https://juniperpublishers.com/online-submission.php 